\title{
Impact of COVID-19 on Acute MI and Percutaneous Coronary Intervention Rates and Outcomes in South East Asia and the Middle East
}

\author{
Paul Jie Wen Tern $\mathbb{\bullet},{ }^{1,2}$ Yilin Jiang, ${ }^{2}$ Yee How Lau, ${ }^{2,3}$ Wael Almahmeed $\mathbb{\bullet},{ }^{4}$ S Gunavathy Selvaraj $\mathbb{\bullet},{ }^{5}$ Jack Wei Chieh Tan $\mathbb{(},{ }^{2}$

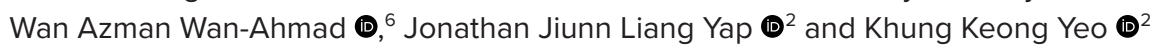

\begin{abstract}
1. Department of Medicine, Singapore General Hospital, Singapore; 2. Department of Cardiology, National Heart Centre Singapore, Singapore; 3. Singapore Cardiac Data Bank, National Heart Centre Singapore, Singapore; 4. Heart and Vascular Institute, Cleveland Clinic Abu Dhabi, Abu Dhabi, United Arab Emirates; 5. National Heart Association of Malaysia, Kuala Lumpur, Malaysia; 6. Department of Medicine, University Malaya Medical Center, Kuala Lumpur, Malaysia
\end{abstract}

\begin{abstract}
Background: Previous studies have reported mixed findings regarding the effects of COVID-19 on percutaneous coronary intervention (PCI) and acute MI (AMI) procedural volumes and case fatalities, as well as on ST-elevation MI (STEMI) door-to-balloon time (DTB). This study characterised the effects of COVID-19 on AMI and PCI volumes and mortality outcomes in countries from Asia and the Middle East, which faced repeated waves of COVID-19. Methods: Pooled data on AMI and PCI case volumes were collected in 4-weekly blocks from Malaysia, Singapore and Abu Dhabi from 2019 (pre-COVID-19) and 2020 (during COVID-19). These were compared against reported COVID-19 case numbers. Case fatality rates, STEMI patient demographics and STEMI DTB times were compared between the pre- and during COVID-19 periods. Results: During the COVID-19 pandemic, there was a comparative reduction in non-STEMI (NSTEMI) cases in Singapore (from 814 to 722; $p=0.025$ ) and Malaysia (from 925 to 604; $p<0.001$ ), but not in Abu Dhabi (from 144 to 188; $p=0.010$ ). PCl volumes fell significantly in Singapore (from 13,089 to 11,449; $p=0.020$ ), but not in Malaysia or Abu Dhabi. STEMI volume remained similar before and during COVID-19. There were no significant differences in in-hospital mortality for NSTEMI, STEMI or PCI between the two periods. Conclusion: COVID-19 resulted in a fall in NSTEMI and PCI cases, potentially as a result of patients deferring contact with healthcare institutions. With appropriate protocols and systems, it is possible to provide coronary intervention services in the middle of a pandemic without compromising on mortality or DTB outcomes.
\end{abstract}

\section{Keywords}

COVID-19, acute MI, percutaneous coronary intervention, case volume, mortality, door-to-balloon time

Disclosure: KKY is editor-in-chief, JJLY is an associate editor and WA is on the editorial board of the Journal of Asian Pacific Society of Cardiology; this did not influence peer review. All other authors have no conflicts of interest to disclose.

Acknowledgements: The authors thank the National Heart Association of Malaysia, all the NCVD investigators and all the sites that contributed towards the National Cardiovascular Disease Registry for permission to publish this manuscript.

Data Availability: The data that support the findings of this study are available on request from the corresponding author. The data are not publicly available due to privacy or ethical restrictions.

Ethical Statement: This study was entirely based on registry data and approved by the relevant institutional review boards. Informed consent was not needed because anonymised registry data was used.

Received: 13 August 2021 Accepted: 4 November 2021 Citation: Journal of Asian Pacific Society of Cardiology 2022;1:e05. DOI: https://doi.org/10.15420/japsc.2021.12 Correspondence: Khung Keong Yeo, National Heart Centre Singapore, 5 Hospital Drive, Singapore 169609. E: yeo.khung.keong@singhealth.com.sg

Open Access: This work is open access under the CC-BY-NC 4.0 License which allows users to copy, redistribute and make derivative works for non-commercial purposes, provided the original work is cited correctly.

Since the outbreak of the severe acute respiratory syndrome coronavirus 2 pandemic in 2019, COVID-19 has spread across the globe, resulting in millions of deaths worldwide. Beyond an immediate impact on mortality and morbidity, this pandemic has also had secondary ramifications for the provision of healthcare as hospitals change existing workflows to accommodate the screening and treatment of COVID and governments impose lockdown measures that directly and indirectly affect patients' presentation to hospitals.

Studies have been published about the effect of the COVID-19 pandemic on procedural volumes of elective percutaneous coronary intervention $(\mathrm{PCl})$, as well as on the presentations and outcomes of acute MI (AMI). ${ }^{1-5}$ Many of these studies only capture the perspective of a single centre in a particular country. Furthermore, study findings are mixed, with some studies reporting a decrease in non-ST segment elevation MI (NSTEMI) or ST-elevation MI (STEMI) presentations since the onset of the pandemic, and others finding no significant difference, particularly in the STEMI caseload. ${ }^{1-5}$ Similarly, reported effects on door-to-balloon (DTB) time and mortality outcomes are mixed.

The aim of this study was to investigate the effects of the COVID-19 pandemic on $\mathrm{AMI}$ and $\mathrm{PCl}$ rates in countries from Asia and the Middle East to gain an insight into the burden COVID-19 was placing on cardiovascular care. This research is especially pertinent because many of these countries are facing repeated waves of COVID-19, and lessons drawn from earlier experiences will be instructive in preparing for future outbreaks. 
Figure 1: Acute MI Case Volumes Compared Against COVID-19 Case Numbers and National Lockdown Measures

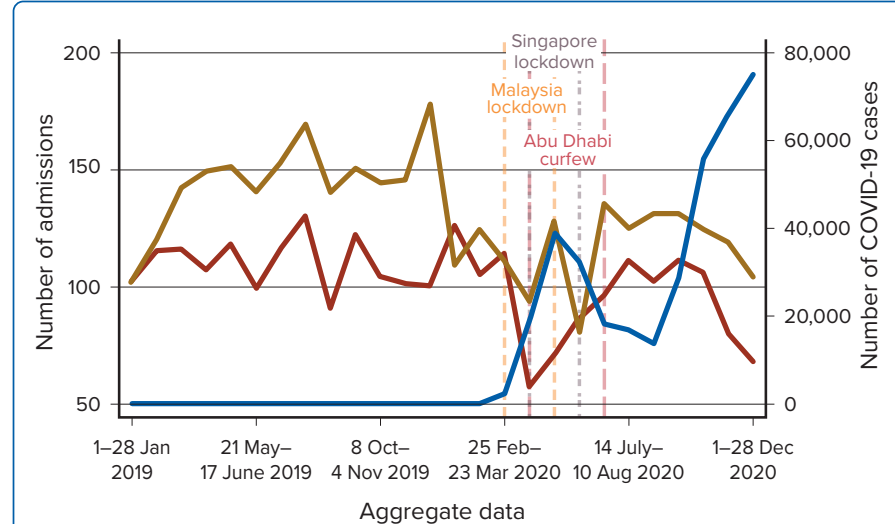

Aggregate data
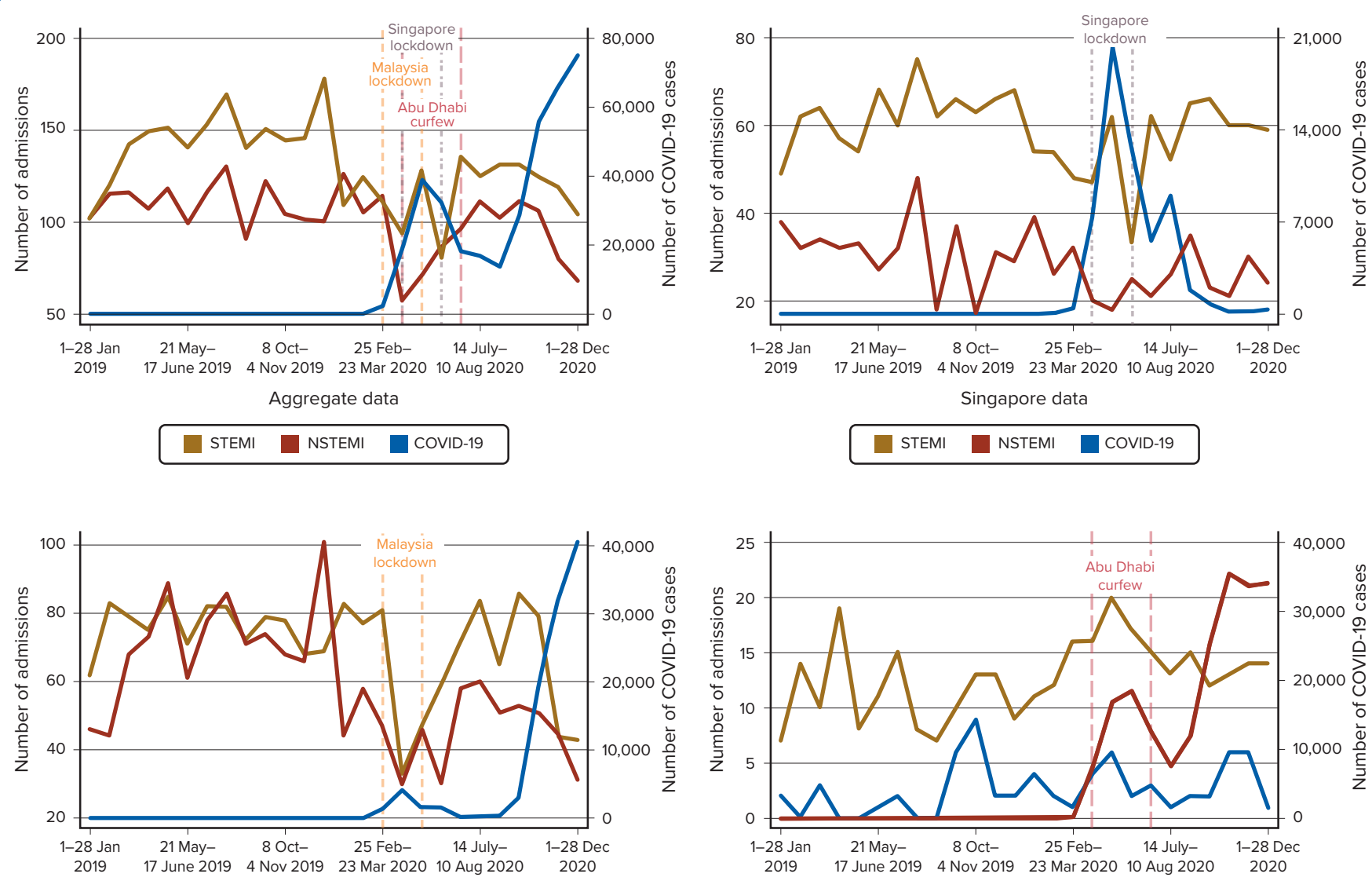

Malaysia data

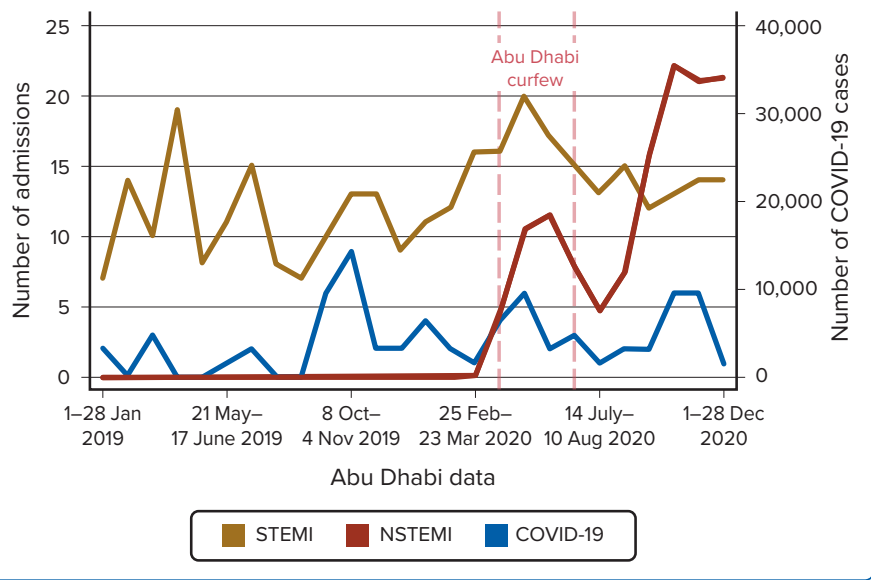

The vertical dotted lines on the plots represent the respective lockdown periods in Singapore and Malaysia, and the daytime partial curfew implemented in Abu Dhabi. NSTEMI = non-ST segment elevation MI; STEMI = ST-elevation MI.

\section{Methods}

Member countries from the Asian Pacific Society of Cardiology were invited to submit pooled data on cases with discharge diagnoses of AMI or PCl, as defined by prespecified ICD codes. Records for admissions for AMI were further subdivided into diagnoses of NSTEMI and STEMI. Inhospital case fatality data were collected for each of these admissions.

In addition, data on patient demographics, comorbidities and DTB time were collected for STEMI admissions. We chose STEMI cases for closer analysis because STEMI is a well-defined clinical entity, with established guidelines around the diagnosis and management of the condition, thus making it a good substrate for comparison of patient profiles before and during the COVID-19 pandemic.

Three centres responded to the call for data: the National Heart Association of Malaysia, which indexes all PCl and AMI data in Malaysia; the National Heart Centre Singapore, a tertiary hospital with the highest $\mathrm{PCl}$ case volume in Singapore; and the Cleveland Clinic Abu Dhabi, a private tertiary hospital in Abu Dhabi. AMl and $\mathrm{PCl}$ case volumes were reported in 4-weekly blocks and plotted against COVID-19 case numbers in each respective country for the corresponding time block (Figures 1 and 2).

\section{Statistical Analysis}

Statistical significance was set at two-tailed $p<0.05$. Continuous variables are presented as the median with interquartile range (IQR) and categorical variables are presented as frequencies and percentages. Comparisons between the pre- and during COVID-19 periods were made using X-squared or Fisher exact tests, as appropriate, for categorical variables and twosample $t$-tests or the Kruskal-Wallis test for continuous variables. The relative risk of mortality was calculated based on $2 \times 2$ contingency tables. Percentage changes were calculated by comparing the admissions and procedural volumes of the respective 4-week blocks for 2019 with the same period in 2020 .

All statistical analyses were conducted using Stata version 16 (StataCorp).

\section{Results}

\section{Acute MI}

Overall, 3,661 patients were admitted for AMI during the pre-COVID-19 period, compared with 2,968 during the COVID-19 period $(p<0.001)$. Although there was no difference in the number of STEMI admissions before and during the COVID-19 period (1,420 versus 1,233; $p=0.081)$, there was a significant reduction in NSTEMI admissions (1,883 versus 1,514; $\mathrm{p}<0.001$; Tables 1 and 2).

Looking at data from individual countries, both Singapore and Malaysia experienced a reduction in total AMI admissions, driven primarily by a reduction in NSTEMI presentations. In Singapore, NSTEMI cases fell from 814 before the pandemic to 722 during the pandemic $(p=0.025)$. Similarly, in Malaysia, NSTEMI cases fell from 925 before the pandemic to 604 
Figure 2: Percutaneous Coronary Intervention Case Volumes Compared Against COVID-19 Case Numbers and National Lockdown Measures

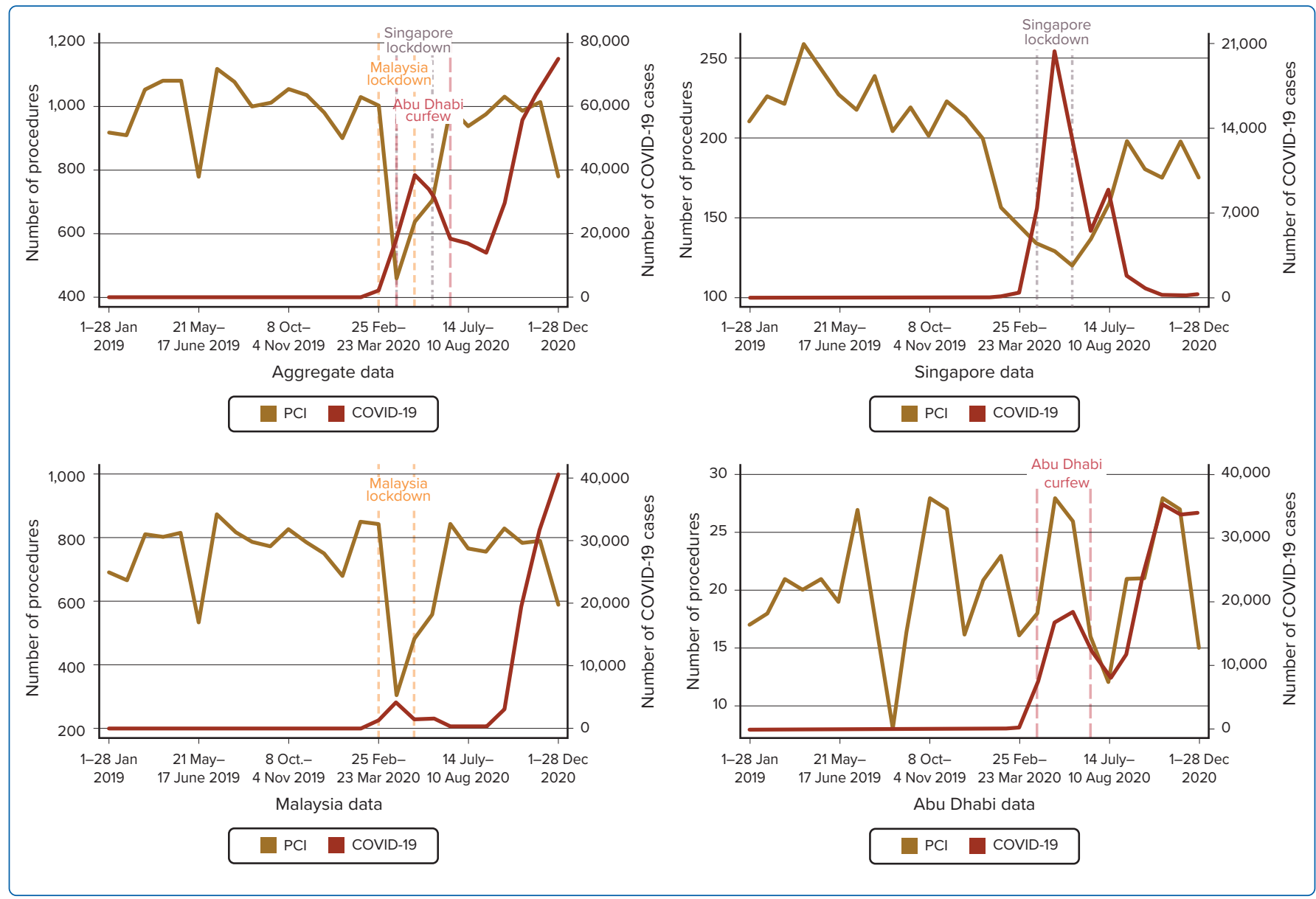

The vertical dotted lines on the plots represent the respective lockdown periods in Singapore and Malaysia, and the daytime partial curfew implemented in Abu Dhabi. PCl = percutaneous coronary intervention.

during the pandemic $(p<0.001)$. However, in Abu Dhabi, there was a significant increase in NSTEMI cases (144 to 188; $p=0.010$ ). There was no significant difference in STEMI cases from before to during the pandemic in any of the three countries.

Patients admitted with STEMI during the COVID-19 period, compared with those admitted prior to the pandemic, were less likely to have diabetes (35.0\% versus $38.7 \%$; $p=0.030$ ), more likely to have dyslipidaemia $(50.7 \%$ versus $41.2 \%$; $p 0.001)$, more likely to have had prior coronary artery bypass grafting $(1.9 \%$ versus $0.8 \% ; p=0.004)$ and more likely to have had prior coronary artery disease or $\mathrm{PCl}(16.6 \%$ versus $10.9 \%$; $\mathrm{p}<0.001)$. Overall, there was a significant decrease in the proportion of cases achieving a DTB time of $\leq 90$ minutes during the COVID-19 period (59.89\% versus $76.81 \%$; $p<0.001$ (Table 3).

In Malaysia, there was a significant reduction in proportion of cases with a DTB time $\leq 90$ minutes during the pandemic (39.00\% versus $71.21 \%$; $\mathrm{p}<0.001)$. However, there was no difference in the proportion of cases with a DTB time $\leq 90$ minutes in Singapore and Abu Dhabi with $>95 \%$ of cases having a DTB $\leq 90$ minutes in both countries. There was no significant difference before and during COVID-19 in in-hospital mortality for STEMI patients (5.49\% versus $4.62 \%$; $p=0.309$ ) or in in-hospital mortality for NSTEMI patients (3.03\% versus $3.43 \%$; $p=0.503$ ). Similarly, individual country analysis did not yield any significant differences in case fatality rates for STEMI or NSTEMI patients before and during COVID-19 (Table 4).

\section{$\mathrm{PCl}$ Volume}

Overall, there was a significant decrease in $\mathrm{PCl}$ cases from before to during the COVID-19 period $(13,089$ versus 11,$449 ; p=0.020)$. This was driven mostly by data from Singapore, where the number of $\mathrm{PCl}$ cases decreased from 2,902 before the pandemic to 2,107 during the pandemic $(p<0.001)$. In contrast, the $\mathrm{PCl}$ caseload in Malaysia and Abu Dhabi remained relatively constant $(p>0.05)$. Overall, there was no significant difference in the case fatality rate from before to during the COVID-19 pandemic (1.55\% versus $1.44 \%$, respectively; $p=0.480)$.

\section{Discussion}

Data pertaining to the impact of COVID-19 on cases of AMI are varied. Several centres have reported a decrease in admissions during the pandemic, ${ }^{1,2,6}$ whereas others have found no significant difference compared with pre-COVID-19 levels. ${ }^{5}$ With regard to the type of MI, most studies have shown a decrease in NSTEMI admissions during the COVID-19 pandemic, but mixed results pertaining to STEMI presentations. ${ }^{3,7}$

Similarly, in the present study there was a decrease in NSTEMI admissions, but we did not find any significant difference in STEMI presentations between the two periods. It is conceivable that STEMI patients experience more severe symptoms that will push them to seek medical attention. Furthermore, they will also have distinct ECG abnormalities that prompt urgent referral to tertiary centres by primary care or emergency medical services. This stands in contrast to the symptoms in NSTEMI, which may 
Table 1: Comparison of Case Volumes in Singapore, Malaysia and Abu Dhabi Before and During the COVID-19 Pandemic

\begin{tabular}{|c|c|c|c|c|c|c|}
\hline \multirow{3}{*}{ Overall } & \multirow{2}{*}{$\begin{array}{l}\text { Total No. Cases } \\
\text { 2019-2020 }\end{array}$} & \multicolumn{2}{|c|}{ Before COVID-19 } & \multicolumn{2}{|c|}{ During COVID-19 } & \multirow{3}{*}{$\begin{array}{l}\text { p-value } \\
\text { (K-W test) }\end{array}$} \\
\hline & & \multirow[t]{2}{*}{$\begin{array}{l}\text { Total No. } \\
\text { Cases }\end{array}$} & \multirow[t]{2}{*}{$\begin{array}{l}\text { No. Cases per 4-week } \\
\text { block, Median (IQR) }\end{array}$} & \multirow[t]{2}{*}{$\begin{array}{l}\text { Total No. } \\
\text { Cases }\end{array}$} & \multirow[t]{2}{*}{$\begin{array}{l}\text { No. Cases per 4-week } \\
\text { Block, Median (IQR) }\end{array}$} & \\
\hline & & & & & & \\
\hline \multicolumn{7}{|l|}{ Procedural } \\
\hline $\mathrm{PCl}$ cases & 24,538 & 13,089 & $1,035(979-1,075)$ & 11,449 & $976(779-1,004)$ & 0.020 \\
\hline Primary PCI & 1,994 & 1,247 & $94(90-105)$ & 747 & $53(43-67)$ & $<0.001$ \\
\hline \multicolumn{7}{|l|}{ Admissions } \\
\hline AMI & 6,629 & 3,661 & 285 (269-297) & 2,968 & $241(206-253)$ & $<0.001$ \\
\hline STEMI & 2,653 & 1,420 & 107 (101-116) & 1,233 & 102 (80-111) & 0.081 \\
\hline NSTEMI & 3,397 & 1,883 & 145 (140-151) & 1,514 & $124(109-128)$ & $<0.001$ \\
\hline \multicolumn{7}{|l|}{ Singapore } \\
\hline \multicolumn{7}{|l|}{ Procedural } \\
\hline $\mathrm{PCl}$ cases & 5,009 & 2,902 & $221(213-227)$ & 2,107 & 159 (137-181) & $<0.001$ \\
\hline Primary PCl & 843 & 493 & $39(34-42)$ & 350 & $24(23-28)$ & 0.002 \\
\hline \multicolumn{7}{|l|}{ Admissions } \\
\hline AMI & 2,846 & 1,574 & $123(118-128)$ & 1,272 & $97(92-102)$ & $<0.001$ \\
\hline STEMI & 748 & 408 & $32(29-34)$ & 340 & $25(21-30)$ & 0.076 \\
\hline NSTEMI & 1,536 & 814 & $63(60-66)$ & 722 & $59(52-62)$ & 0.025 \\
\hline \multicolumn{7}{|l|}{ Malaysia } \\
\hline \multicolumn{7}{|l|}{ Procedural } \\
\hline PCl cases & 18,998 & 9,928 & 786 (750-816) & 9,070 & 766 (589-829) & 0.522 \\
\hline Primary PCI & 1,060 & 719 & $58(51-61)$ & 341 & $23(18-37)$ & $<0.001$ \\
\hline \multicolumn{7}{|l|}{ Admissions } \\
\hline AMI & 3,384 & 1,916 & $147(134-160)$ & 1,468 & 127 (93-131) & 0.001 \\
\hline STEMI & 1,838 & 985 & 78 (71-82) & 853 & $72(47-81)$ & 0.317 \\
\hline NSTEMI & 1,529 & 925 & $71(66-78)$ & 604 & $47(44-53)$ & $<0.001$ \\
\hline \multicolumn{7}{|l|}{ Abu Dhabi } \\
\hline \multicolumn{7}{|l|}{ Procedural } \\
\hline $\mathrm{PCl}$ cases & 531 & 259 & 19 (18-21) & 272 & $21(16-26)$ & 0.699 \\
\hline Primary PCl & 91 & 35 & $2(2-3)$ & 56 & $4(2-7)$ & 0.052 \\
\hline \multicolumn{7}{|l|}{ Admissions } \\
\hline AMI & 399 & 171 & $13(9-16)$ & 228 & $17(15-19)$ & 0.016 \\
\hline STEMI & 67 & 27 & $2(0-2)$ & 40 & $2(2-4)$ & 0.104 \\
\hline NSTEMI & 332 & 144 & $10(8-13)$ & 188 & $14(13-16)$ & 0.010 \\
\hline
\end{tabular}

AMI = acute $M I ; I Q R=$ interquartile range; $K-W=$ Kruskal-Wallis; $P C I=$ percutaneous coronary intervention; NSTEMI = non-ST segment elevation MI; STEMI = ST-elevation MI.

be less typical and less intense, such that they are tolerated by patients, who refrain from presenting to hospital for fear of being exposed to COVID-19.

There is high health avoidance behaviour during pandemics, especially when there are unconfirmed beliefs about modes of transmission, increased perceived severity of the outbreak and increased perception of susceptibility. ${ }^{8,9}$ Indeed, nadir levels of NSTEMI and STEMI admissions in Malaysia and Singapore were reached during the respective lockdown periods in each country. In particular, NSTEMI and STEMI admissions in Malaysia were lowest during the period 24 March-20 April 2020, which coincided with the start of the Movement Control Order (18 March-3 May 2020). This is despite the fact that the absolute number of COVID-19 cases was higher in the latter part of 2020. This suggests that fear surrounding the initial outbreak of a hitherto unknown virus, along with the added psychological burden of a government-imposed curfew, may have been holding patients back from presenting to hospital, despite the fact that they were still allowed to seek medical attention during these lockdown periods.

NSTEMI and STEMI admissions in Abu Dhabi rose in tandem with the number of COVID-19 cases in the country, which is in contrast to data from Singapore and Malaysia. This reflects the impact of local policy, because the Cleveland Clinic Abu Dhabi was designated by the public health authorities as a centre responsible for care of non-COVID-19 conditions. This resulted in NSTEMI and STEMI cases being diverted to this centre. 
Table 2: Demographics of Patients Admitted With ST-Elevation MI Before and During the COVID-19 Pandemic

\begin{tabular}{|c|c|c|c|c|}
\hline & Overall 2019-2020 & Before COVID-19 & During COVID-19 & p-value \\
\hline \multicolumn{5}{|l|}{ Overall } \\
\hline No. patients & 3,220 & 1,854 & 1,366 & \\
\hline Mean $( \pm S D)$ age (years) & $56.9 \pm 12.2$ & $56.9 \pm 12.1$ & $56.8 \pm 12.8$ & 0.819 \\
\hline Male sex & $2,744(85.2)$ & $1,570(84.7)$ & 1,174 (85.9) & 0.318 \\
\hline Diabetes & $1,196(37.1)$ & $718(38.7)$ & $478(35.0)$ & 0.030 \\
\hline Hypertension & $1,707(53.0)$ & $984(53.1)$ & $723(52.9)$ & 0.935 \\
\hline Dyslipidaemia & $1,455(45.2)$ & $763(41.2)$ & $692(50.7)$ & $<0.001$ \\
\hline Smoking (current or past) & $1,568(48.7)$ & $861(46.4)$ & 707 (51.8) & 0.003 \\
\hline ESRD on dialysis & $55(1.7)$ & $26(1.4)$ & $29(2.1)$ & 0.119 \\
\hline Any CKD & $169(5.2)$ & $90(4.9)$ & $79(5.8)$ & 0.243 \\
\hline Prior CABG & $40(1.2)$ & $14(0.8)$ & $26(1.9)$ & 0.004 \\
\hline Prior CVA & $50(1.6)$ & $23(1.2)$ & $27(2.0)$ & 0.095 \\
\hline Prior known CAD or $\mathrm{PCl}$ & 429 (13.3) & $202(10.9)$ & $227(16.6)$ & $<0.001$ \\
\hline \multicolumn{5}{|l|}{ Singapore } \\
\hline No. patients & 748 & 408 & 340 & \\
\hline Mean $( \pm S D)$ age (years) & $62.5 \pm 12.4$ & $62.4 \pm 12.5$ & $62.6 \pm 12.4$ & 0.764 \\
\hline Male sex & $601(80.3)$ & $332(81.4)$ & $269(79.1)$ & 0.440 \\
\hline Diabetes & $320(42.8)$ & $181(44.4)$ & $139(40.9)$ & 0.338 \\
\hline Hypertension & $470(62.8)$ & $263(64.5)$ & $207(60.9)$ & 0.313 \\
\hline Dyslipidaemia & $514(68.7)$ & $270(66.2)$ & $244(71.8)$ & 0.101 \\
\hline Smoking (current or past) & 382 (51.1) & $205(50.2)$ & $177(52.1)$ & 0.621 \\
\hline ESRD on dialysis & $23(3.1)$ & $8(2.0)$ & $15(4.4)$ & 0.053 \\
\hline Any CKD & $109(14.6)$ & $54(13.2)$ & $55(16.2)$ & 0.256 \\
\hline Prior CABG & $31(4.1)$ & $7(1.7)$ & $24(7.1)$ & $<0.001$ \\
\hline Prior CVA & $15(2.0)$ & $7(1.7)$ & $8(2.4)$ & 0.536 \\
\hline Prior known $\mathrm{CAD}$ or $\mathrm{PCl}$ & $237(31.7)$ & $97(23.8)$ & $140(41.2)$ & $<0.001$ \\
\hline \multicolumn{5}{|l|}{ Malaysia } \\
\hline No. patients & 2,366 & 1,402 & 964 & \\
\hline Mean $( \pm S D)$ age (years) & $55.2(11.6)$ & $55.4(11.5)$ & $54.9(11.7)$ & \\
\hline Male sex & $2,043(86.3)$ & 1,196 (85.3) & $847(87.9)$ & 0.075 \\
\hline Diabetes & $832(35.2)$ & $518(36.9)$ & $314(32.6)$ & 0.029 \\
\hline Hypertension & $1,186(50.1)$ & $699(49.9)$ & $487(50.5)$ & 0.752 \\
\hline Dyslipidaemia & $883(37.3)$ & $471(33.6)$ & $412(42.7)$ & $<0.001$ \\
\hline Smoking (current or past) & 1,121 (47.4) & $630(44.9)$ & $491(50.9)$ & 0.004 \\
\hline ESRD on dialysis & $31(1.3)$ & $18(1.3)$ & $13(1.3)$ & 0.892 \\
\hline Any CKD & $55(2.3)$ & $35(2.5)$ & $20(2.1)$ & 0.504 \\
\hline Prior CABG & $7(0.3)$ & $6(0.4)$ & $1(0.1)$ & 0.154 \\
\hline Prior CVA & $29(1.2)$ & $14(1.0)$ & $15(1.6)$ & 0.226 \\
\hline Prior known $\mathrm{CAD}$ or $\mathrm{PCl}$ & $174(7.4)$ & $99(7.1)$ & $75(7.8)$ & 0.510 \\
\hline \multicolumn{5}{|l|}{ Abu Dhabi } \\
\hline No. patients & 106 & 44 & 62 & \\
\hline Mean $( \pm S D)$ age (years) & $53.1(11.7)$ & $52.1(10.6)$ & $53.8(12.5)$ & \\
\hline Male sex & $100(94.3)$ & $42(95.5)$ & 58 (93.5) & 0.676 \\
\hline Diabetes & $44(41.5)$ & $19(43.2)$ & $25(40.3)$ & 0.768 \\
\hline Hypertension & $51(48.1)$ & $22(50.0)$ & $29(46.8)$ & 0.743 \\
\hline Dyslipidaemia & $58(54.7)$ & $22(50.0)$ & $36(58.1)$ & 0.411 \\
\hline Smoking (current or past) & $65(61.3)$ & $26(59.1)$ & $39(62.9)$ & 0.691 \\
\hline ESRD on dialysis & $1(0.9)$ & $0(0.0)$ & $1(1.6)$ & 0.397 \\
\hline
\end{tabular}


Table 2: Cont.

\begin{tabular}{|c|c|c|c|c|}
\hline & Overall 2019-2020 & Before COVID-19 & During COVID-19 & p-value \\
\hline \multicolumn{5}{|l|}{ Abu Dhabi } \\
\hline Any CKD & $5(4.7)$ & $1(2.3)$ & $4(6.5)$ & 0.317 \\
\hline Prior $\mathrm{CABG}$ & $2(1.9)$ & $1(2.3)$ & $1(1.6)$ & 0.806 \\
\hline Prior CVA & $6(5.7)$ & $2(4.5)$ & $4(6.5)$ & 0.676 \\
\hline Prior known $\mathrm{CAD}$ or $\mathrm{PCl}$ & $18(17.0)$ & $6(13.6)$ & $12(19.4)$ & 0.440 \\
\hline
\end{tabular}

Unless indicated otherwise, data are given as $n$ (\%). $C A B G=$ coronary artery bypass grafting; $C A D=$ coronary artery disease; $C K D=$ chronic kidney disease; $C V A=$ cerebrovascular accident; $E S R D=$ end-stage renal disease; $P C I=$ percutaneous coronary intervention.

Table 3: Number of Patients Meeting a Door-To-Balloon Time of $\leq 90$ min Before and During the COVID-19 Pandemic

\begin{tabular}{llll} 
& DTB Time $\leq 90$ min & p-value $\left(\mathbf{X}^{2}\right)$ \\
\hline Ovefore COVID-19 & During COVID-19 & \\
\hline NHCS & $709(76.81)$ & $318(59.89)$ & $<0.001$ \\
\hline NHAM & $164(96.47)$ & $129(96.27)$ & 0.925 \\
\hline Abu Dhabi & $33(97.06)$ & $133(39.00)$ & $<0.001$ \\
\hline
\end{tabular}

Unless indicated otherwise, data are given as $n(\%)$. DTB = door-to-balloon; $N H A M=$ National Heart Association of Malaysia; NHCS = National Heart Centre Singapore.

In this study, the proportion of patients achieving a DTB of $\leq 90$ minutes was reduced in Malaysia, but unchanged in Singapore and Abu Dhabi. Notably, of the three countries, Malaysia pursued a thrombolysis-first strategy, with primary $\mathrm{PCl}$ only if the patient was known to be COVID-19negative or as rescue therapy in the event of failed thrombolysis with medical staff in full personal protective equipment. ${ }^{10}$ This would likely explain the difference in DTB time among the three countries. Other studies with similar findings have attributed differences in DTB time to the time taken to perform preadmission screening chest X-rays and to ascertain travel and contact histories and symptomatology in patients whose COVID-19 status is unknown.111 Unfamiliarity of the emergency department (ED) with new workflows may also be a contributing factor, with subsequent recovery in the DTB time towards the later stages of the pandemic. ${ }^{12}$ Data from Singapore and Abu Dhabi suggest that with appropriate and well-rehearsed ED workflows, a strategy of primary $\mathrm{PCl}$ can still be pursued for STEMI care, with little effect on overall DTB time. This is especially important in a prolonged pandemic response, given the superior outcomes of a primary $\mathrm{PCl}$ strategy. ${ }^{13}$

Nevertheless, despite the increase in DTB time, we did not find a corresponding significant increase in STEMI in-hospital mortality. Similarly, case fatality rates for NSTEMI, $\mathrm{PCl}$ and primary $\mathrm{PCl}$ remained largely constant. This is in keeping with reports from other studies, and is testament to the robustness of these medical systems in maintaining a high level of cardiovascular care despite the pandemic., 1,6,14

Data on $\mathrm{PCl}$ volumes provide some insights into how COVID-19 has affected elective procedures. The decrease in $\mathrm{PCl}$ in the present study was driven largely by data from Singapore, where there was an active push to reschedule non-urgent elective cardiac catheterisation. The decline in $\mathrm{PCl}$ in Singapore started with the onset of the COVID-19 pandemic and reached a nadir during the government-imposed 'circuit breaker' (7 April-1 June 2020). The fall can be explained by guidance from the Ministry of Health in Singapore and individual institutions to postpone non-urgent cases to free up bed space in anticipation of a surge in COVID-19-related admissions. Recovery ensued as healthcare systems adapted.

\section{Limitations}

Although this study sheds light on the effect of COVID-19 on cardiovascular care in Singapore, Malaysia and Abu Dhabi, the insights are largely limited to these countries and constrained by the particular circumstances of each country's response to COVID-19. In addition, the data from Singapore and Abu Dhabi are from a single centre and may not be fully generalisable. As we highlighted earlier, reports on the effects of COVID-19 are context dependent and can differ greatly. Furthermore, our study concluded in December 2020, when case numbers in Malaysia and Abu Dhabi were still increasing. Further research into the effects of these second waves will be very instructive in ascertaining how healthcare systems deal with far higher COVID-19 case numbers despite being armed with protocols and experience in operating under pandemic conditions.

\section{Conclusion}

This study has shown that the COVID-19 pandemic has led to a fall in NSTEMI, but not STEMI, admissions. A reduction in the proportion of STEMI patients achieving a DTB time of $\leq 90$ minutes may be related to the thrombolysis-first approach pursued by Malaysia. PCl volumes decreased, primarily driven by the deferral of non-urgent procedures in Singapore. There was no significant effect of the COVID-19 pandemic on in-hospital mortality. $\square$

\section{Clinical Perspective}

- The COVID-19 pandemic resulted in a fall in non-ST segment elevation MI but not ST-elevation MI (STEMI) admissions in Singapore and Malaysia. This decrease appears to be related more to the implementation of nationwide lockdown measures rather than absolute COVID-19 case numbers.

- A reduction in the proportion of STEMI patients achieving a door-to-balloon time of $\leq 90$ min may be related to the thrombolysis-first approach pursued by Malaysia.

- PCl volumes decreased due to deferral of non-urgent procedures, especially in Singapore.

- There was no significant effect of the COVID-19 pandemic on case fatalities from acute $\mathrm{Ml}$ admissions or percutaneous coronary intervention procedures. 
Table 4: Comparison of Case Fatality Rates for Percutaneous Coronary Intervention, Primary PCl, ST-Elevation MI and Non-ST-Elevation MI Admissions Before and During the COVID-19 Pandemic

\begin{tabular}{|c|c|c|c|c|c|c|}
\hline & \multicolumn{2}{|l|}{ Before COVID-19 } & \multicolumn{2}{|l|}{ During COVID-19 } & \multirow[t]{2}{*}{ RR (95\% Cl) } & \multirow[t]{2}{*}{$p$-value $\left(x^{2}\right)$} \\
\hline & Total No. Cases & Mortality, n (\%) & Total No. Cases & Mortality, n (\%) & & \\
\hline \multicolumn{7}{|l|}{ Overall } \\
\hline \multicolumn{7}{|l|}{ Procedural } \\
\hline $\mathrm{PCl}$ cases & 13,089 & $203(1.55)$ & 11,449 & $165(1.44)$ & $0.9(0.8-1.1)$ & 0.480 \\
\hline Primary $\mathrm{PCl}$ & 1,247 & $91(7.30)$ & 747 & $60(8.03)$ & $1.1(0.8-1.5)$ & 0.548 \\
\hline \multicolumn{7}{|l|}{ Admissions } \\
\hline STEMI & 1,420 & 78 (5.49) & 1,233 & $57(4.62)$ & $0.8(0.6-1.2)$ & 0.309 \\
\hline NSTEMI & 1,883 & $57(3.03)$ & 1,514 & $52(3.43)$ & $1.1(0.8-1.6)$ & 0.503 \\
\hline \multicolumn{7}{|l|}{ Singapore } \\
\hline \multicolumn{7}{|l|}{ Procedural } \\
\hline $\mathrm{PCl}$ cases & 2,902 & $69(2.38)$ & 2,107 & $54(2.56)$ & $1.1(0.8-1.5)$ & 0.676 \\
\hline Primary $\mathrm{PCl}$ & 493 & $45(9.13)$ & 350 & $42(12.00)$ & $1.3(0.9-2.0)$ & 0.177 \\
\hline \multicolumn{7}{|l|}{ Admissions } \\
\hline STEMI & 408 & $32(7.84)$ & 340 & 28 (8.24) & $1.1(0.6-1.7)$ & 0.844 \\
\hline NSTEMI & 814 & $34(4.18)$ & 722 & $35(4.85)$ & $1.2(0.7-1.8)$ & 0.527 \\
\hline \multicolumn{7}{|l|}{ Malaysia } \\
\hline \multicolumn{7}{|l|}{ Procedural } \\
\hline $\mathrm{PCl}$ cases & 9,928 & $126(1.27)$ & 9,070 & $103(1.14)$ & $0.9(0.7-1.2)$ & 0.400 \\
\hline Primary $\mathrm{PCl}$ & 719 & $45(6.26)$ & 341 & $16(4.69)$ & $0.7(0.4-1.3)$ & 0.306 \\
\hline \multicolumn{7}{|l|}{ Admissions } \\
\hline STEMI & 985 & $43(4.37)$ & 853 & $28(3.28)$ & $0.8(0.5-1.2)$ & 0.230 \\
\hline NSTEMI & 925 & $20(2.16)$ & 604 & $14(2.32)$ & $1.1(0.5-2.1)$ & 0.840 \\
\hline \multicolumn{7}{|l|}{ Abu Dhabi } \\
\hline \multicolumn{7}{|l|}{ Procedural } \\
\hline $\mathrm{PCl}$ cases & 259 & 8 (3.09) & 272 & $8(2.94)$ & $1.0(0.4-2.5)$ & 0.921 \\
\hline Primary PCl & 35 & $1(2.86)$ & 56 & $2(3.57)$ & $1.3(0.1-13.3)$ & 0.853 \\
\hline \multicolumn{7}{|l|}{ Admissions } \\
\hline STEMI & 27 & $3(11.11)$ & 40 & $1(2.50)$ & $0.2(0.0-2.1)$ & 0.145 \\
\hline NSTEMI & 144 & $3(2.08)$ & 188 & $3(1.60)$ & $0.8(0.2-3.7)$ & 0.741 \\
\hline
\end{tabular}

NSTEMI = non-ST segment elevation MI; STEMI = ST-elevation MI.

1. Rattka M, Dreyhaupt J, Winsauer $\mathrm{C}$, et al. Effect of the COVID-19 pandemic on mortality of patients with STEMI: a systematic review and meta-analysis. Heart 2021;107:482-7. https://doi.org/10.1136/heartjnl-2020-318360; PMID: 33334863.

2. Meenakshisundaram $R$, Senthilkumaran $S$, Thirumalaikolundusubramanian $\mathrm{P}$, et al. Status of acute myocardial infarction in southern India during COVID-19 lockdown: a multicentric study. Mayo Clin Proc Innov Qual Outcomes 2020;4:506-10. https://doi.org/10.1016/j. mayocpiqo.2020.06.010; PMID: 33043274.

3. Wu J, Mamas M, Rashid M, et al. Patient response, treatments, and mortality for acute myocardial infarction during the COVID-19 pandemic. Eur Heart J Qual Care Clin Outcomes 2021;7:238-46. https://doi.org/10.1093/ehjqcco/ qcaa062: PMID: 32730620.

4. Elliott JM, Crozier IG. Decreases in cardiac catheter laboratory workload during the COVID-19 level 4 lockdown in New Zealand. Intern Med J 2020;50:1000-3. https://doi. org/10.1111/imj.14922; PMID: 32881225.

5. Li YH, Huang WC, Hwang JJ. No reduction of ST-segment elevation myocardial infarction admission in Taiwan during coronavirus pandemic. Am J Cardiol 2020;131:133-4. https:// doi.org/10.1016/j.amjcard.2020.06.030; PMID: 32713656

6. Showkathali R, Yalamanchi R, Sankeerthana MP, et al. Acute coronary syndrome admissions and outcome during COVID19 pandemic - report from large tertiary centre in India. Indian Heart J 2020;72:599-602. https://doi.org/10.1016/j. ihj.2020.09.005; PMID: 33357652

7. Choudhary R, Singh K, Choudhary D, et al. Patterns of care and mortality outcomes in patients admitted with acute coronary syndrome during coronavirus disease 2019 pandemic in India. Coron Artery Dis 2021;32:590-2. https://doi.org/10.1097/MCA.0000000000001011; PMID: 33471481.

8. Lau JT, Griffiths S, Choi KC, Tsui HY. Avoidance behaviors and negative psychological responses in the general population in the initial stage of the H1N1 pandemic in Hong Kong. BMC Infect Dis 2010;10:139. https://doi.org/10.1186/14712334-10-139; PMID: 20509887.

9. Moroni F, Gramegna M, Ajello S, et al. Collateral damage: medical care avoidance behavior among patients with myocardial infarction during the COVID-19 pandemic. JACC Case Rep 2020;2:1620-4. https://doi.org/10.1016/j. jaccas.2020.04.010; PMID: 32835261.

10. National Heart Association of Malaysia. ACS during COVID-
19 pandemic. 2020. https://www.malaysianheart. org/?p=highlights\&a=1430 (accessed 21 June 2021).

11. Tam CCF, Cheung KS, Lam S, et al. Impact of coronavirus disease 2019 (COVID-19) outbreak on ST-segment-elevation myocardial infarction care in Hong Kong, China. Circ Cardiovasc Qual Outcomes 2020;13:e006631. https://doi. org/10.1161/CIRCOUTCOMES.120.006631; PMID: 32182131.

12. Chew NW, Sia CH, Wee HL, et al. Impact of the COVID-19 pandemic on door-to-balloon time for primary percutaneous coronary intervention - results from the Singapore Western STEMI Network. Circ J 2021;85:139-49. https://doi. org/10.1253/circi.CJ-20-0800; PMID: 33162491.

13. Keeley EC, Boura JA, Grines CL. Primary angioplasty versus intravenous thrombolytic therapy for acute myocardial infarction: a quantitative review of 23 randomised trials. Lancet 2003;361:13-20. https://doi.org/10.1016/S01406736(03)12113-7; PMID: 12517460.

14. Mohamed MO, Banerjee A, Clarke S, et al. Impact of COVID19 on cardiac procedure activity in England and associated 30-day mortality. Eur Heart J Qual Care Clin Outcomes 2021;7:247-56. https://doi.org/10.1093/ehjqcco/qcaa079; PMID: 33079204 